\title{
METHODS OF WEAR TESTS FOR HERMETIC RECIPROCATING COMPRESSORS: AN OVERVIEW
}

\author{
I. M. G. ALMEIDA ${ }^{1 *}$, C. R. F. BARBOSA ${ }^{2}$ and F. A. O. FONTES \\ ${ }^{1}$ Instituto Federal de Educação, Ciência e Tecnologia do Rio Grande do Norte \\ ${ }^{2}$ Universidade Federal do Rio Grande do Norte \\ igor.almeida@ifrn.edu.br
}

Article submitted in April/2014 and accepted in April/2016

DOI: $10.15628 /$ holos.2016.2078

\begin{abstract}
The refrigerants being used in vapor compression processes have specific thermodynamic properties, which are decisive for the performance of the compressor of the system. The Montreal and the Kyoto protocols initiated a discussion of alternative refrigerants, which lead to new requirements of the compressor. The reliability of reciprocal compressors has become a leading field for compressor research. One of the main tools in the reliability field is accelerated degradation/life testing (ADT or ALT). These tests are designed to provide life estimates or to define lower bounds of product/parts reliability at shortened time periods. The objective of this paper is to discuss the literature on accelerated life testing of reciprocating hermetic compressors, focusing on the wear of
\end{abstract}

mechanical components. Several test methodologies are discussed as well as the procedures used to wear quantification. It is noted that there are numerous test methodologies. This fact can be attributed to the lack of standardization updated. Most authors have been focused the tests development to assess the scuffing occurrence in components. The evaluation of wear (qualitative and quantitative) is carried through optical microscopy techniques, scanning electron microscopy, surface roughness, physical-chemical analysis of the oil and electric power consumption. Test methodologies are presented based on critical analysis of the existing literature and the current scenario of refrigerants and lubricants development.

KEYWORDS: hermetic reciprocating compressor, wear, reliability, accelerated tests

\section{MÉTODOS DE ENSAIO DE DESGASTE PARA COMPRESSORES HERMÉTICOS ALTERNATIVOS: UMA VISÃO GERAL}

\section{RESUMO}

Os refrigerantes utilizados em sistemas por compressão de vapor possuem propriedades termodinâmicas específicas que são decisivas para a performance do compressor destes sistemas. A confiabilidade de compressores alternativos se tornou um campo de pesquisa importante. Uma das principais ferramentas no campo da confiabilidade são os ensaios de degradação e vida acelerada ( $A D T$ ou ALT). Estes ensaios são projetados para fornecer estimativas de vida ou definir limites inferiores da confiabilidade dos componentes/produto em curtos períodos de tempo. 0 objetivo deste artigo é discutir a literatura científica sobre ensaios de vida acelerada de compressores herméticos alternativos de refrigeração, focando no desgaste de componentes mecânicos. Diversas metodologias são discutidas, bem como os procedimentos para quantificação de desgaste. Constata-se diversas metodologias distintas. Este fato pode ser atribuído à escassez de normalização atualizada. Muitos autores focam no desenvolvimento de ensaios para avaliação da ocorrência de scuffing (desgaste adesivo severo) nos componentes. A avaliação de desgaste (quantitativa e qualitativa) é realizada através de técnicas de microscopia óptica, rugosidade superficial, análises físico-químicas do óleo e consumo de potência. As metodologias são apresentadas através de análise crítica da literatura existente e no presente cenário de desenvolvimento de refrigerantes e lubrificantes.

PALAVRAS-CHAVE: compressores alternativos herméticos, desgaste, confiabilidade, testes acelerados 


\section{INTRODUCTION}

The refrigerants being used in vapor compression processes have specific thermodynamic properties, which are decisive for the performance of the compressor of the system. The Montreal and the Kyoto protocols initiated a discussion of alternative refrigerants, which lead to new requirements of the compressor (Suess et al., 2000).

The last two decades are characterized with various pressures on synthetic refrigerants from the point of their environmental effects. The first wave was due to ozone depletion when excellent-performing and easy-to-work-with CFCs were replaced with HFCs. The recent pressure is due to the global warming impact of HFCs (Hrnjak, 2010).

The request of new low GWP options based on either synthetic (man made) refrigerants or natural (naturally occurring) materials have to offer high efficiency in addition to environmental friendliness and safety for people and property. That situation will open new possibilities for drop in refrigerants along options for natural refrigerants.

As conventional refrigerants phased out, isobutane (R600a) emerged as the main alternative in refrigeration industry. Hydrocarbons (HCs) such as R600a are viable substitutes as they possess favorable refrigerants properties. However, their compatibility and performance with compressor oils are being investigated (Sariibrahimoglu et al., 2010). For R600a the COP is superior to both R134a and R12, however the long term wear and durability of equipment using this refrigerant is unknown (Garland and Hadfield, 2005).

As an example of how complicated our world can be, let's just look at compressor tribology (that is, lubrication of pistons, cylinders and bearings), with that of other machinery. Unlike changing the oil in your car, which is done often during the life of a vehicle, compressor oil for automobile and residential air conditioning, which is used under much more severe and extreme conditions, is rarely replaced. This fact alone speaks for a major technical accomplishment from Tribology perspective.

Although better COP values are achieved with $\mathrm{HC}$ refrigerants, wear life related issues need to be resolved since limited literature is available. Possible problem areas include motor/crankshaft journals; crank pin/connecting rod bearings, piston/cylinder sliding interface and the inlet/exhaust flapper valves (Na et al., 1997).

The reliability of reciprocating compressors has become a leading field for compressor research. Quality control techniques are now known and have been shown to be efficient means to ensure quality at a short time horizon, allowing customers to focus on long term product quality features. Such features may be defined as product reliability measures. One of the main tools in the reliability field is accelerated life testing (ALT). These tests are designed to provide life estimates or to define lower bounds of product/parts reliability at shortened periods of time.

Compressors are designed to last for several years. The fast changing world and demand for new and improved products urges the use of design techniques that help to reduce the product development cycle time without jeopardizing the quality of the design process. This makes ALT an essential part in the compressor design cycle (Feldhaus and Coit, 1998). 
From a technological perspective, the concept of sustainable development ensures that environmental costs are no longer seen as a burden but as an opportunity for cost reduction, product innovation and increased product value (Hawken, et al. 1999). This requires that economic growth be uncoupled from the free use of resource and energy consumption, so shifting from an era of quantitative sufficiency to qualitative satisfaction (Tomiyama and Umeda, 1997).

Industrial ecology is defined as a broad activity applied to both products and processes which aids initially in the evaluation and subsequently in the minimisation of environmental impacts (Ishii, 1998). Undoubtedly, it would be impractical to include all the environmental impacts surrounding a particular system but a sensitivity towards ensuring a high probability of environmental preference must be sought whilst maintaining technological and economical feasibility. The effective use of natural resources and the consequent reduction in waste and emissions are influenced by the consumption of energy throughout the use phase of active products (Hanssen 1995; Alting and Legarth 1995; Dannheim, et al. 1997) as well as by the extension of their useful life (Keoleian and Menerey 1994; Legarth and Alting 1995).

It is no exaggeration to suggest that simple, low cost, and precise bearings along with tribological capabilities are the critical force in supporting the advancement of today's compact and high-performance compressor (Nishioka, 1998).

Tribological characteristics play a significant role in both of these product attributes as a consequence of friction and wear, which curtail product durability and hence product efficiency, performance as well as life extension (Ciantar, 2000).

The interrelation between surfaces in relative motion and product durability was highlighted in a UK Government study, commissioned in 1964, to investigate the position of lubrication education and research and to highlight the needs industry had in this respect. This report is commonly referred to as the Jost Report after Professor H. Peter Jost, chairman of the working group subsequently formed. It identifies several weaknesses in the way lubrication (or tribology) was being dealt with in industry. One of the key conclusions is that industrial designers overlooked tribological issues and were unable to foresee their economic implications as a result of energy consumption, product efficiency and product life extension. Similar conclusions are reached by a subsequent study commissioned by the then Energy Research and Development Administration of the US (Ciantar, 2000).

Savings due to tribological characteristics result from the energy consumption during product use or, in the case of failure, from a reduction in the re-manufacture of parts or complete products and in the production of materials for replacement parts or products (Jost apud Ciantar, 2000).

Any potential cost savings resulting from the above considerations will also imply savings on environmental impact. If tribological constraints are appropriately addressed in an attempt to reduce costs by improving the use phase of products, then both product efficiency and product durability will reduce the overall impact on the environment.

The objective of this paper is to discuss the literature on the reliability theory applied to the reciprocating hermetic compressors, focusing on the wear of mechanical components._Several test methodologies are discussed as well as the procedures used to wear quantification. Test 
methodologies are presented based on critical analysis of the existing literature and the current scenario of refrigerants and lubricants development.

\section{RBTT: RELIABILITY BASED ON THERMODYNAMICS AND TRIBOLOGY}

Tribological phenomena occur in systems encompassing a broad spectrum of length scales, from common machine, instrument and tool elements, such as a ball bearing and its race groove, a pair of spur gear involute teeth, cams and shafts, components of polishing, machining and patterning instruments, to high density data storage devices, micro-machines and bio-tribological system, such as synovial joints and total joint replacements. Common to all tribological systems is the importance of interfacial configuration. Thus, studies of the basic origins of tribological phenomena should focus on the investigation of contact mechanisms and on properties of interfaces between solids (both static and dynamic), interfacial structure and adhesion, flow, and rheology of confined liquid under shearing (Yang, 2008).

The function of a tribotechnical system is to use the system structure to convert input variables (e.g., input torque, input speed, input type of motion, and sequence of motions) into technically utilizable output variables (e.g., output torque, output speed, output motion) (Valis et al., 2012).

Life and degradation tests of various forms are used to establish assurance that the compressor will perform over an extended period to satisfy the guarantee. They may be used to determine a possible weakness in design or the effect of surface variations on the life of the moving parts.

The modes of failure for a hermetic refrigeration compressor can be grouped into three general categories. These are, 1) electrical, 2) mechanical and 3) chemical. The mechanical group should be such failures as broken valves, broken connecting rods, broken suspension springs, assembly screws or bolts loosening with use, seized bearings or shafts, etc. Design techniques having advanced as they have, combined with good material and manufacturing control makes this group a small portion of the field returns (Erdman, 1972).

The tests with hermetic compressors are not run until failure. Their fundamentals for valuation are the physical and chemical changes determined after completion of the tests in the testing periods given or in the course of the test (Lorenz and Rochhausen, 1976). Accelerated degradation tests (ADT) has widely been used by manufacturers and testers for qualitative explanation of a degradation process, and comparative analysis. The degradation process obtained for different design aspects could be used to predict the most robust design to tolerate service stresses.

In reliability testing, most global companies focus on the accelerating life test (ALT). This method can help shorten the product development cycles, costs less money, and clarify diverse design faults. However, there are some caveats of using ALT: any failures after ALT may not represent those occurring under field conditions. This problem usually arises because of the inconsistency of the direction and magnitude of the load, such as force or pressure in system dynamics. Moreover, the number of test samples and the test times are insufficient to uncover infrequent failure modes. ALT should be performed with sufficient samples and test time, and ALT equipment can and should be designed to match product loads (Woo and O'Neal, 2006). 
Refrigerator reliability problems in the field often occur when the refrigerator parts cannot endure the repetitive stresses due to internal or external forces over a specified period of time. When the energy flow in the refrigeration system can be expressed as the product of an effort and a flow variable, forces may be generally expressed as efforts. Efforts and flow in the hermetic compressors are represented by the pressure differential $(\Delta P)$ and refrigerant volume flow rate (Woo et al., 2011).

\subsection{Scuffing wear context}

A few among many otherwise highly successful lubricated sliding components fail catastrophically and without warning. This sudden mode of failure is often called scuffing. The phenomenon of scuffing has been known for many years and numerous attempts have been made to define it (Yoon and Cusano, 1999).

Scuffing is another tribological failure, which is of major concern for compressor manufactures as it occurs abruptly, leading to complete destruction of the sliding pair, thus rendering the device non-functional (Demas et al., 2005 apud Mishra and Polycarpou, 2011).

In the context of air conditioning compressor surfaces, the understanding of the scuffing mechanism can provide insight to avoiding detrimental component failure and result in an increase in operational lifetime (Suh et al., 2006).

Previous studies have shown the piston pin/connecting rod bearing to be the most susceptible since, for the domestic refrigerator compressor, only the gudgeon pin/small end bearing operates within the boundary condition, the others being hydrodynamic journal bearings. Figure 1 shows the friction parts of reciprocating compressors.

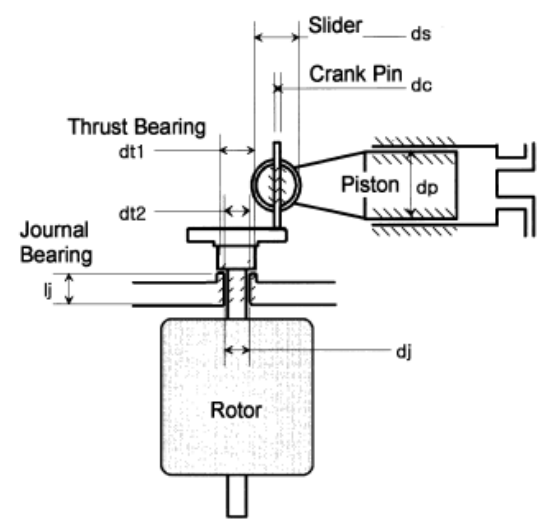

Figure 1. Friction parts of reciprocating compressor (Adapted from Na et al., 1997).

One such contact in a reciprocating compressor is the conforming connection between the die-cast aluminium alloy connecting rod and the hardened steel gudgeon pin. Under normal operation, conditions are similar to hydrodynamic lubrication, but at stop/start, condition is similar to boundary lubrication (Ciantar et al., 1999).

Scuffing causes catastrophic damage on tribological surfaces, mainly affecting the topmost surface layers at depths ranging from sub-micron to micron. Factors influencing scuffing include contact pressure, sliding velocity, contact temperature, lubricant and lubrication regime, surface topography, material composition and structure, and film coatings of surfaces in contact (Suh et al., 2006). 
The reason why scuffing remains a poorly understood phenomenon is that it involves various damage mechanisms such as mechanical, chemical, metallurgical, and thermal reactions (Cho and Lee, 2011).

Recently, it has been suggested that the main cause of scuffing is associated with subsurface failure. Tests has been developed under dry sliding conditions and starved lubrication. Figure 2 presents the tribo-contact structure and levels of interaction.

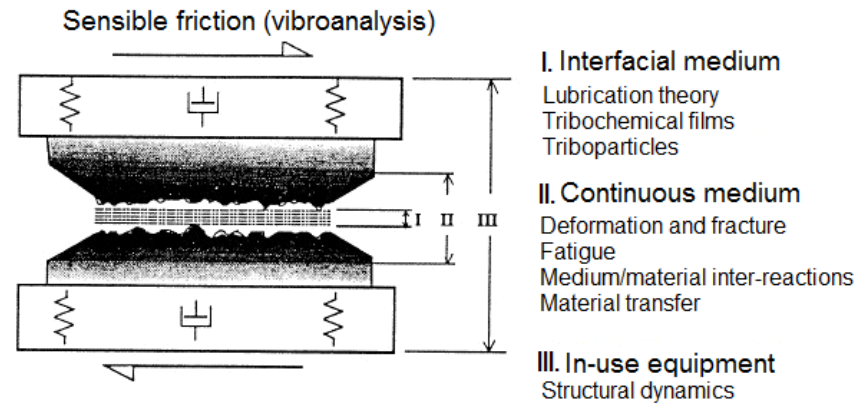

Figure 2. Heterogeneous real tribo-contact interactions. (Bulnes et al., 2012)

Scuffing failure originates at the internal parameters level (level I), however catastrophic aspects are late detected (post-mortem) on the external level (levels II and III). Scuffing prevention can be carried through the reliability based on tribology (RBT) focused on surface texture topology optimization (level II), certainly the texture affects the lubrication regimes. That is, ultimately, affects the friction, but only in boundary lubrication regime, where there is partial metal-metal contact.

Thus, it is evident that a RBT involves many complex issues that has to do mainly with the internal parameters, external to a lesser extent, and certainly unexpected parameters that affect what we mean by friction. The relationship between these parameters results in a complex problem, it is not possible to establish application limits of the concepts involved. You can only establish probable "tribological behaviour" of the system (Bulnes et al., 2012).

According to van Drogen (2005), in the literature there two classes of scuffing failure criteria. The first class (true friction power intensity), proposed by Horng (1998), is based on the critical scuffing power intensity or its variants. The second class is postulating a critical scuffing temperature (based on the Blok theory) of some sort. The first class only takes into account the heat generation and does not pay attention to heat transfer effects. On the contrary, the temperature based criteria do account for heat transfer effects. Therefore, they are assumed to be more realistic.

However, in addition a certain fascination with wear processes exists based on the idea that since wear is such a universally observed process it may be directly related to the fundamental nature of materials and processes (Klamecki, 1980).

There are many different methods and standards which are used for wear evaluation, besides a branch between methods used for experimental research on wear, friction and lubrication of the compression mechanism. Many authors use specific standards for wear tests on metallic specimens used in compressors (phenomenological) by using of tribometers and machines for evaluating lubricity of oil/refrigerant blend. These authors are concerned with the development 
of new materials and surface coatings (Yoon et al., 1998; Garland and Hadfield, 2005; Sariibrahimoglu et al., 2009; De Mello et al., 2009).

Moreover, some authors focusing on the compressor evaluation as a component of the overall refrigeration system. This favors obtaining a result more consistent with the actual situation of the component application. These authors apply different methodologies for accelerating the compressor life for tribological analysis purposes, based on the actual load parameters (Safari and Hadfield, 1998; Ciantar et al., 1999; Ciantar, 2000, Woo and O'Neal, 2006; Woo et al., 2011).

\subsection{Accelerated degradation/life testing}

Accelerated testing is a powerful tool that can be effectively used in two very different ways: in a qualitative or in a quantitative manner. Qualitative accelerated testing is used primarily to identify failures and failure modes while quantitative accelerated testing is used to make predictions about a products life characteristics (e.g., MTTF, B10 life, etc.) under normal use conditions.

Overstress testing (is the most common form of accelerated testing) consists of running a product at higher than normal levels of some accelerating stress(es) to shorten product life or to degrade product performance faster. Typical accelerating stresses are temperature, voltage, mechanical load, thermal cycling, humidity, and vibration (Nelson, 1992).

The stress loading in an accelerated test can be applied various ways. They include constant, cyclic, step, progressive, and random stress loading, according to Figure 3.

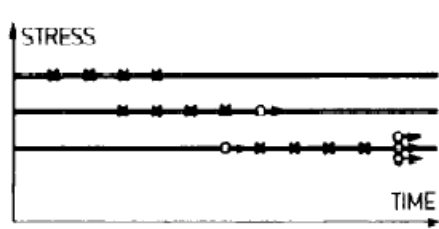

(A)

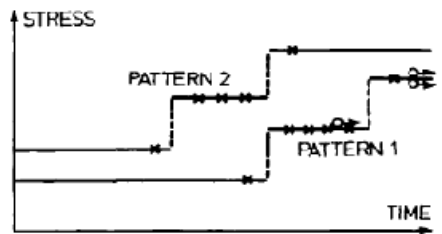

(B)

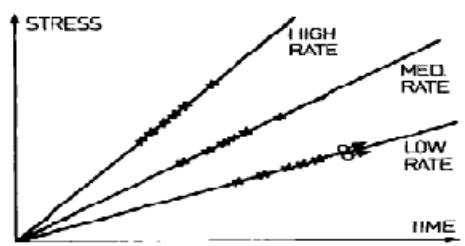

(C)

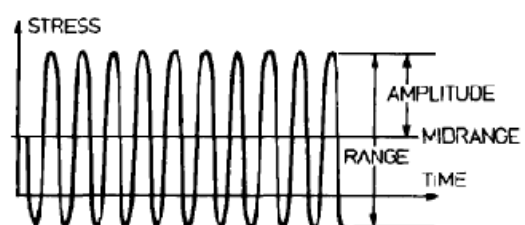

(D)

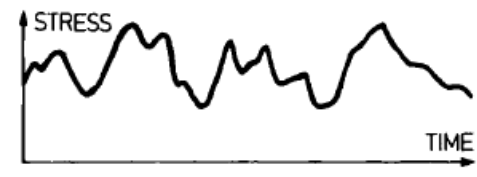

(E)

Figure 3 - Load stresses in accelerated tests: (A) constant, (B) step, (C) progressive, (D) cyclic e (E) random (Nelson, 1992).

Actually in the compressor, most of the contact of moving parts is through areas to make hydrodynamic lubrication. A compressor's working condition is not as severe compared to the point or line contact method. Most of the wear occurs at the start and stop conditions in the compressor. The piston pressure is about 10 bar. The contact pressure between piston and slider is much less then 10 bar ( $1000 \mathrm{kPa}$ ). So that this contact is not important and can be neglected ( $\mathrm{Na}$ et al., 1997). 
The contact area of the crank pin-slider (CP-S) is smaller than that of the piston journalslider (PJ-S). Thus, the contact pressure of the CP-S is higher than that of PJ-S. Table 1 shows the typical stress factors for compressor testing.

Table 1. Summary of most common hermetic compressors ALT procedures: items, stress factors, and typical life period for the occurrence of a failure (Feldhaus and Coit, 1998).

\begin{tabular}{|c|c|c|}
\hline Item & Typical Stress Factor(s) & $\begin{array}{c}\text { Typical Life Period(s) of a } \\
\text { Failure Occurrence }\end{array}$ \\
\hline $\begin{array}{c}\text { Bearings and moving parts (piston, } \\
\text { wrist pin, valves, crankshaft, etc.) }\end{array}$ & $\begin{array}{c}\text { Temperature (oil viscosity) } \\
\text { Pressure differential (equivalent to } \\
\text { mechanical load) } \\
\text { Rotation }\end{array}$ & $\begin{array}{c}\text { Constant failure rate phase } \\
\text { Wear-out phase }\end{array}$ \\
\hline Suction/discharge systems & $\begin{array}{c}\text { Temperature } \\
\text { Humidity } \\
\text { Pressure differential } \\
\text { Vibration }\end{array}$ & All phases of operational life \\
\hline Oil & $\begin{array}{c}\text { Temperature } \\
\text { Humidity }\end{array}$ & Wear-out phase \\
\hline
\end{tabular}

The test under cyclic stress is configured as more consistent with the reality of hermetic compressors operation, since this component operates under the permanent cycling regime (onoff) in actual conditions. The stress (or life) of the compressor depends on the pressure difference suction pressure, Psuc, and discharge pressure, Pdis.

The existing landscape setting of the stresses applied to accelerated testing in hermetic compressor presents well divided in the literature. Some authors and standards (GOST 172401971, McAllister, 1972; Hansen and Finsen, 1992; Sekiya et al., 1998; Ciantar et al., 2000; Woo and O'Neal, 2006) apply the cyclic stress configuration, e.g. the compressor must operate intermittently. Another authors and standardization group (Lieding et al., 1972; DIN 8978, 1983; lizuka et al., 1996; Sunami et al., 1996; Sunami et al., 1998; Sekiya et al, 1998; Slayton and Spauschus, 1998; Ciantar et al., 1999) apply the constant stress configuration, that is, the compressor should operate under a continuous regime.

\subsection{Statistical approach and Arrhenius model}

A statistical model for an accelerated life test consists of 1) a life distribution that represents the scatter in product life and 2 ) a relationship, between life and stress. A model depends on the product, the test method, the accelerating stress, the form of the specimen, and other factors.

Increasing the level of acceleration variables like temperature, humidity, voltage, or pressure can accelerate the chemical or other degradation processes related to specific failure mechanisms. If an adequate physically based statistical model is available to relate failure time to levels of accelerating variables, the model can be used to estimate lifetime or degradation rates at product use conditions (Meeker et al., 1999).

Life times at low stress tend to be longer than those at high stress. Also, the scatter in life is greater at low stress than at high stress. The smooth curve through the data represents "life" as a function of stress. A simple relationship does not describe the scatter in the life of the test units. For each stress level, the units have some statistical distribution of life (Nelson, 1992). 
A more refined model employs a statistical distribution to describe the scatter in life. Thus the model here consists of a combination of a life distribution and a life-stress relationship. Commonly used theoretical life distributions include the exponential, lognormal, and Weibull distributions. The standard accelerated failure time regression models (based on Weibull or lognormal approximations to the failure time distribution at a given stress) are adequate for modeling some simple chemical processes that lead to failure. In other cases, more sophisticated models are required (Meeker and Escobar, 1993)

The relevant acceleration models that should be considered include: Arrhenius Temperature Acceleration for temperature and chemical aging effects, Inverse Power Law for any given stress, Miner's Rule for linear accumulated fatigue damage, Coffin-Manson non-linear mechanical fatigue damage, Peck's Model for temperature and humidity combined effects, Eyring/Black/Kenney models for temperature and voltage acceleration.

The well-known and commonly used models for accelerated testing (e.g., the Arrhenius model for temperature acceleration) have gained acceptance for some applications because of their many successful applications and general agreement of laboratory test results with long-term field performance (Meeker and Escobar, 1993).

Unfortunately, the mechanism of scuffing (severe adhesive wear) is so complicated that it is not easy to predict time to scuffing failures, because the process involves mechanical, chemical, metallurgical and thermal reactions. There is no developed literature in a statistical life and degradation model that considers sliding wear of metals.

A cumulative distribution function $\mathrm{F}(t)$ represents the population fraction failing by age $t$

$$
F(t)=1-e^{-t / \theta}, t \geq 0
$$

$\theta>0$ is the mean time to failure (MTTF). $\theta$ is in the same measurement units as $t$, for example, hours, months, cycles, etc. In some applications, life $t^{\prime}$ under design use is expressed in terms of life $t$ at an accelerated test condition as

$t=A F \cdot t^{\prime}$

Here $A F$ is called the acceleration factor and is assumed known. As above, one can calculate equivalent times $t^{\prime}$ from accelerated times $t$ and estimate the life distribution under design conditions. Typically, different failure modes have different acceleration factors. This is especially so for complex products consisting of assemblies of diverse components. With high overloads not being permissible additional failure mechanisms occur which are not in accordance with the actual failure behaviour (Lorenz and Rochhausen, 1976).

Much of the previous work in this area has focused on modeling life as a function of only one accelerating stress. Developing models for two or more stresses will be important for many real applications. Table 2 presents acceleration factors used for compressors testing available in the literature. 
Table 2. Main acceleration factors for hermetic compressors wear tests stablished in literature.

\begin{tabular}{|c|c|}
\hline Acceleration factor & Compressor type \\
\hline Differential pressure at suction and discharge & Reciprocating, rolling piston, scroll \\
\hline Rotational speed (rpm)/sliding velocity & Scroll, rolling piston \\
\hline Liquid return (flooded cycle) & Rolling piston \\
\hline Compressor housing temperature & Reciprocating \\
\hline Number of cycles & Reciprocating, scroll, rolling piston \\
\hline
\end{tabular}

Woo and O'Neal (2006) presented a sequence of reliability testing, including ALT, they evaluated the compressor reliability with the new failure rate and $B_{x}$ (shape parameter in a Weibull distribution) life. Authors have proposed the Arrhenius model (elevated temperature acceleration) to describe the time to failure. For medium stress, the life-stress model (LS model) has been proposed

$T_{f}=A(S)^{-n} \exp \frac{E_{a}}{k T}=A(\Delta P)^{-n} \exp \frac{E_{a}}{k T}$

where $A$ (frequency factor) and $S$ are constants and are characteristics of the particular chemical reaction, $T f$ is the time to failure, $k$ is Boltzman's constant, $E_{a}$ is the activation energy (an indicator of effect that the covariate - temperature, humidity, etc. - has on the life or the product), $T$ is the absolute temperature and $n$ is the quotient. The authors consider that the pressure differential $(\Delta \mathrm{P})$ develop by the compressor is the stress factor, inducing a chemical reaction (temperature elevation) at the friction parts.

The acceleration factor $(A F)$ is given by:

$A F=\left(\frac{S_{1}}{S_{0}}\right)^{n}=\left(\frac{\Delta P_{1}}{\Delta P_{0}}\right)^{n}\left[\frac{E_{a}}{k}\left(\frac{1}{T_{0}}-\frac{1}{T_{1}}\right)\right]$

where $\mathrm{S}_{1}\left(\right.$ or $\Delta \mathrm{P}_{1}$ ) is medium stress (or pressure difference), and $\mathrm{S}_{0}$ (or $\Delta \mathrm{P}_{0}$ ) is normal stress. The Arrhenius reaction rate equation is given by

$\operatorname{Re}(T)=A \cdot \exp \left(\frac{E_{a}}{k_{b} \cdot T}\right)$

Each failure mechanism can be characterized by a Weibull distribution with inherent shape and scale parameters. So, for a given failure mechanism " $i$ ", the acceleration factor can be written for any temperature $T$

$A F_{i}(T)=\frac{\delta_{i}\left(T_{0}\right)}{\delta_{i}(T)}=\frac{\left[\operatorname{MTTF}\left(T_{0}\right)\right]_{i}}{[\operatorname{MTTF}(T)]_{i}}=\exp \left[\frac{E_{a i}}{k} \cdot\left(\frac{1}{T_{0}}-\frac{1}{T}\right)\right]$ 
Let,

$\varepsilon=\exp \left[\frac{1}{k} \cdot\left(\frac{1}{T_{0}}-\frac{1}{T}\right)\right]$

Then,

$A F_{i}(T)=\varepsilon^{E_{a i}}$

The values of the activation energy are constant for a particular stress or failure mode, but in reality the activation energy may actually vary from one production lot to another, from one version of the product to another and from one failure mechanism to another.

Empirical activation-energy-based reliability models do not account for the physics of failure including component details such as structure and material properties, but have been used to roughly estimate reliability.

$E_{a}=\frac{\ln \left(\sum_{i=1}^{n} p_{i} \cdot \varepsilon^{E_{a i}}\right)}{\ln (\varepsilon)}$

This relation clearly shows that the overall activation energy of the mixed distribution is temperature dependant and cannot be considered as a constant because $\varepsilon$ is temperature dependant.

Generally, acceleration factors are based on physics of failure and established from accelerated tests for all stresses except steady state temperature. Activation energy and thus the acceleration factor is no longer demonstrated by manufacturer tests. In addition to the assumption of a value for the activation energy in most prediction standards, there is also the question of how relevant these values are, since some standards are quite old. This suggests it is no longer justifiable to regard activation energy as a stable physical constant (Bayle and Mettas, 2010).

Tribo-systems are in essence energy driven systems that are subject to thermodynamic constraints. Such constraints, represented in both entropy generation and transport, decide the state of integrity of the materials involved. That is, the degradation of the rubbing materials is also a thermodynamically driven process. The Arrhenius relationship is a simple model that will not adequately describe the effect that temperature has on all chemical reactions (Meeker et al., 2012).

\section{WEAR TESTS OVERVIEW}

\subsection{Experimental arrangements of cycles}

Dirlea et al. (1996) proposed the hot (fully) gas cycle layout for compressors testing. A test point for refrigeration compressors is obtained by imposing three physical variables: pressure at compressor supply $\left(\mathrm{P}_{\text {suc }}\right)$, temperature at compressor supply $\left(\mathrm{T}_{\text {suc }}\right)$ and pressure at compressor discharge $\left(P_{\text {disc }}\right)$. It can be concluded that the method is particularly suitable for long live tests and quality control of compressors. Due to the low charge of refrigerant, the method can be a useful 
tool in investigating compressors behaviour when using alternative refrigerants for which refrigerant charge of the plant is submitted to prescriptions, hydrocarbons for example. Figure 4 shows the cycle layout and the P-h diagram.

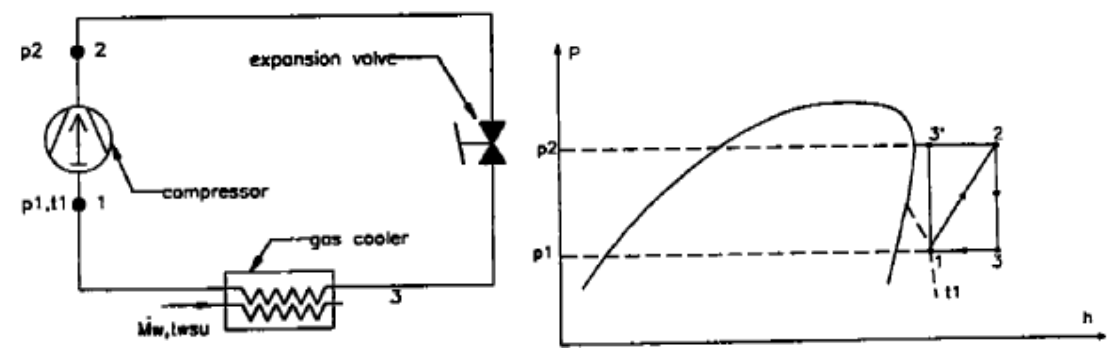

Figure 4. Hot (fully) gas cycle. a) plant layout; b) P-h diagram. (Dirlea et al., 1996)

Convention compressor bench tests using load stands, generally require from 2000 hours to 4000 hours (12 to 24 weeks). Slayton and Spauschus (1998) have proposed a short-term (200 hours), accelerated test protocol has been developed initially for rotary compressors used in airconditioning and small heat pump applications. Figure 5 presents the cycle developed for the tests.

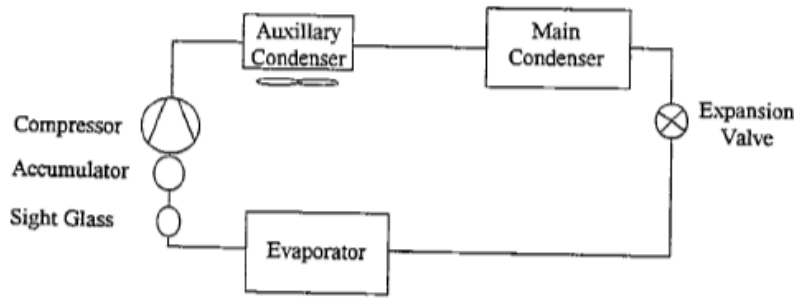

Figure 5. Floodback refrigerant circuit (Slayton and Spauschus, 1998).

At operating test pressures, a certain level of liquid floodback is provided and monitored by sight glass observations. The level of liquid floodback to provide appropriate test acceleration, within the 200 hour test period, was developed from designed experiments and correlated to actual field return compressor cut-apart analyses, to ascertain that the bearing wear modes were consistent with field experience.

Standard wear tests for hermetic compressors (DIN 1973) specify the use of test equipment which operates only in the vapor phase (hot gas). However, to evaluate the electric power required for hermetic compressors, using a vapor-liquid bench test comes closer to the actual refrigerator condition (Hansen and Finsen, 1992; lizuka et al., 1996; Ciantar et al., 1999; Ciantar and Hadfield, 2004).

Ciantar and Hadfield (2004) designed a test rig (liquid/vapor phase) to evaluate the in-use power requirements of a hermetic compressor operating with a variety of working fluids. Tribological characteristics on concentrated contacts within these tested compressors were then studied to interpret any relationship between friction and wear and fluctuations in the monitored power. Figure 6 shows the test rig. 


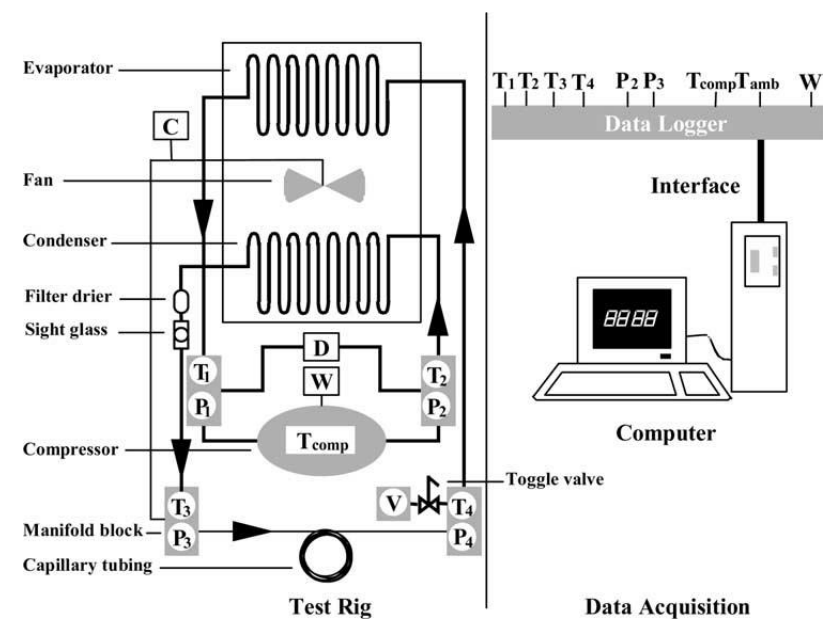

Figure 6. Schematic of compressor test rig (Ciantar and Hadfield, 2004)

\subsection{Wear tests protocols}

Table 3 shows a compilation of the major studies conducted to wear evaluation of hermetic compressors. The table shows the compressor type, refrigerant used, the test rig and experimental methodology developed and techniques which are used to wear measure on components.

Table 3. Summary of wear tests protocols for hermetic compressors.

\begin{tabular}{|c|c|c|c|c|c|}
\hline Author & $\begin{array}{c}\text { Refrigerants/Lu } \\
\text { bricants }\end{array}$ & $\begin{array}{c}\text { Compressor } \\
\text { type/application }\end{array}$ & \multicolumn{2}{|c|}{ Method/test conditions } & Information \\
\hline \multirow[b]{2}{*}{$\begin{array}{l}\text { Hansen e } \\
\text { Finsen } \\
(1992)\end{array}$} & \multirow{2}{*}{$\begin{array}{l}\text { R12, R134a, } \\
\text { HCFC-22/HFC- } \\
\text { 152a/HCFC-124 } \\
\text { blend }\end{array}$} & \multirow[b]{2}{*}{$\begin{array}{l}\text { Reciprocating/Domesti } \\
\text { c refrigerator }\end{array}$} & \multicolumn{2}{|c|}{$\begin{array}{c}\text { - Standard vapor-liquid refrigeration } \\
\text { cycle }\end{array}$} & \multirow{2}{*}{$\begin{array}{l}\text { Wear depth of } \\
\text { reciprocating } \\
\text { mechanical } \\
\text { components. } \\
\text { Deposits in valves. }\end{array}$} \\
\hline & & & \multicolumn{2}{|c|}{$\begin{array}{c}-P_{\text {disc }}=2.16 \mathrm{MPa} \\
-P_{\text {suc }}=0.26 \mathrm{MPa} \\
\text { - Winding motor temperature }=150^{\circ} \mathrm{C} \\
\text { - Intermittent operation }=27 \mathrm{~min}(\text { on }) / 3 \\
\min (\text { off }) ; \\
\text { - Duration }=2000-4000 \text { hours; }\end{array}$} & \\
\hline \multirow{4}{*}{$\begin{array}{l}\text { lizuka et } \\
\text { al. (1996) }\end{array}$} & \multirow{4}{*}{ Lubricant: POE } & \multirow{4}{*}{ Scroll/Air conditioner } & \multicolumn{2}{|c|}{ Standard vapor-liquid refrigeration cycle } & \multirow{4}{*}{$\begin{array}{l}\text { Surface roughness } \\
\text { (Ra); } \\
\text { Wear } \\
\text { quantification of } \\
\text { superior and } \\
\text { inferior bearings; }\end{array}$} \\
\hline & & & High velocity & High load & \\
\hline & & & $\begin{array}{c}\mathrm{P}_{\text {suc }}=0.40 \mathrm{MPa} \\
\mathrm{P}_{\text {disc }}=1.57-1.87 \mathrm{MPa} \\
\text { Speed }=8250 \mathrm{rpm}\end{array}$ & $\begin{array}{c}\mathrm{P}_{\text {suc }}=0.59 \\
\mathrm{MPa} \\
\mathrm{P}_{\text {disc }}=2.85- \\
2.94 \mathrm{MPa} \\
\text { Speed }= \\
5700 \mathrm{rpm}\end{array}$ & \\
\hline & & & \multicolumn{2}{|c|}{$\begin{array}{l}\text { Duration = } 90 \text { days ( } 2160 \text { hours); } \\
\text { Continuous operation; }\end{array}$} & \\
\hline $\begin{array}{l}\text { Sunami et } \\
\text { al. (1996) }\end{array}$ & $\begin{array}{l}\text { R12, R134a, R22 } \\
\text { Lubricants: AB, } \\
\text { POE, Mineral oil. }\end{array}$ & $\begin{array}{l}\text { Rolling piston/Air } \\
\text { conditioner }\end{array}$ & \multicolumn{2}{|c|}{$\begin{array}{c}\text { - Fully gas cycle; } \\
-\mathrm{P}_{\text {suc }}=0.157 \text { e } 0.098 \mathrm{MPa} \\
\text { - } \mathrm{P}_{\text {disc }}=2.94 \text { e } 1.67 \mathrm{MPa} \\
-\mathrm{T}_{\text {disc }}=110 \text { e } 150^{\circ} \mathrm{C} ; \\
\text {-Duration }=2000 \text { hours; } \\
\text { - Continuous operation; }\end{array}$} & $\begin{array}{l}\text { Surface roughness } \\
\text { (Ra) of sliding } \\
\text { components: shaft, } \\
\text { bearings, etc. } \\
\text { Wear depth (mm). }\end{array}$ \\
\hline $\begin{array}{l}\text { Sunami et } \\
\text { al. (1998) }\end{array}$ & $\begin{array}{c}\text { R22, R407C } \\
\text { Lubricants: AB, } \\
\text { POE, Mineral oil. }\end{array}$ & $\begin{array}{l}\text { Rolling piston/Air } \\
\text { conditioner }\end{array}$ & \multicolumn{2}{|c|}{$\begin{array}{l}\text { - Fully gas cycle; } \\
-\mathrm{P}_{\text {suc }}=0.379 \mathrm{MPa} \\
-\mathrm{P}_{\text {disc }}=2.85 \mathrm{MPa} \\
-\mathrm{T}_{\text {disc }}=100^{\circ} \mathrm{C}\end{array}$} & $\begin{array}{l}\text { Surface roughness } \\
\text { (Ra): sliding } \\
\text { components; }\end{array}$ \\
\hline
\end{tabular}




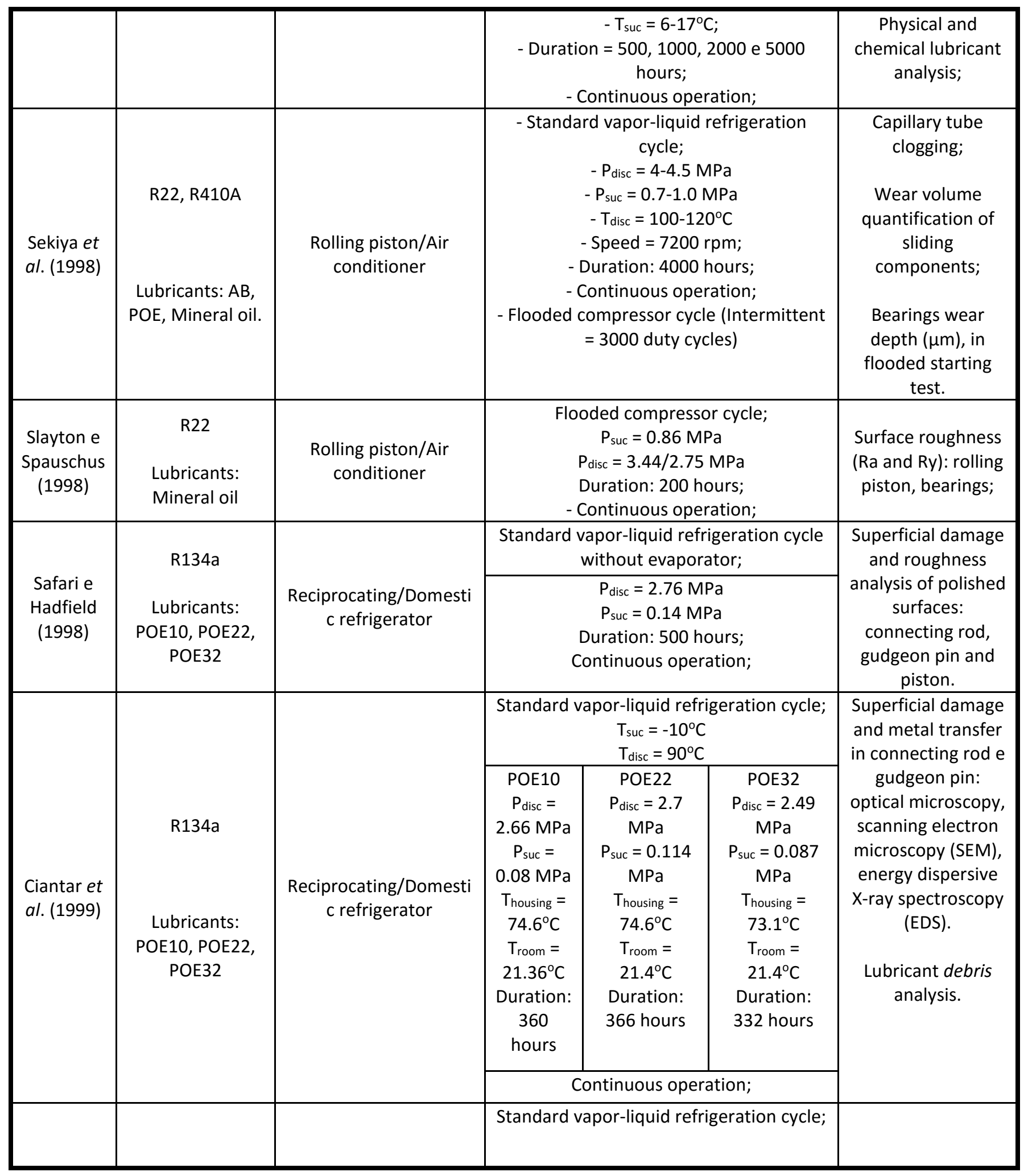




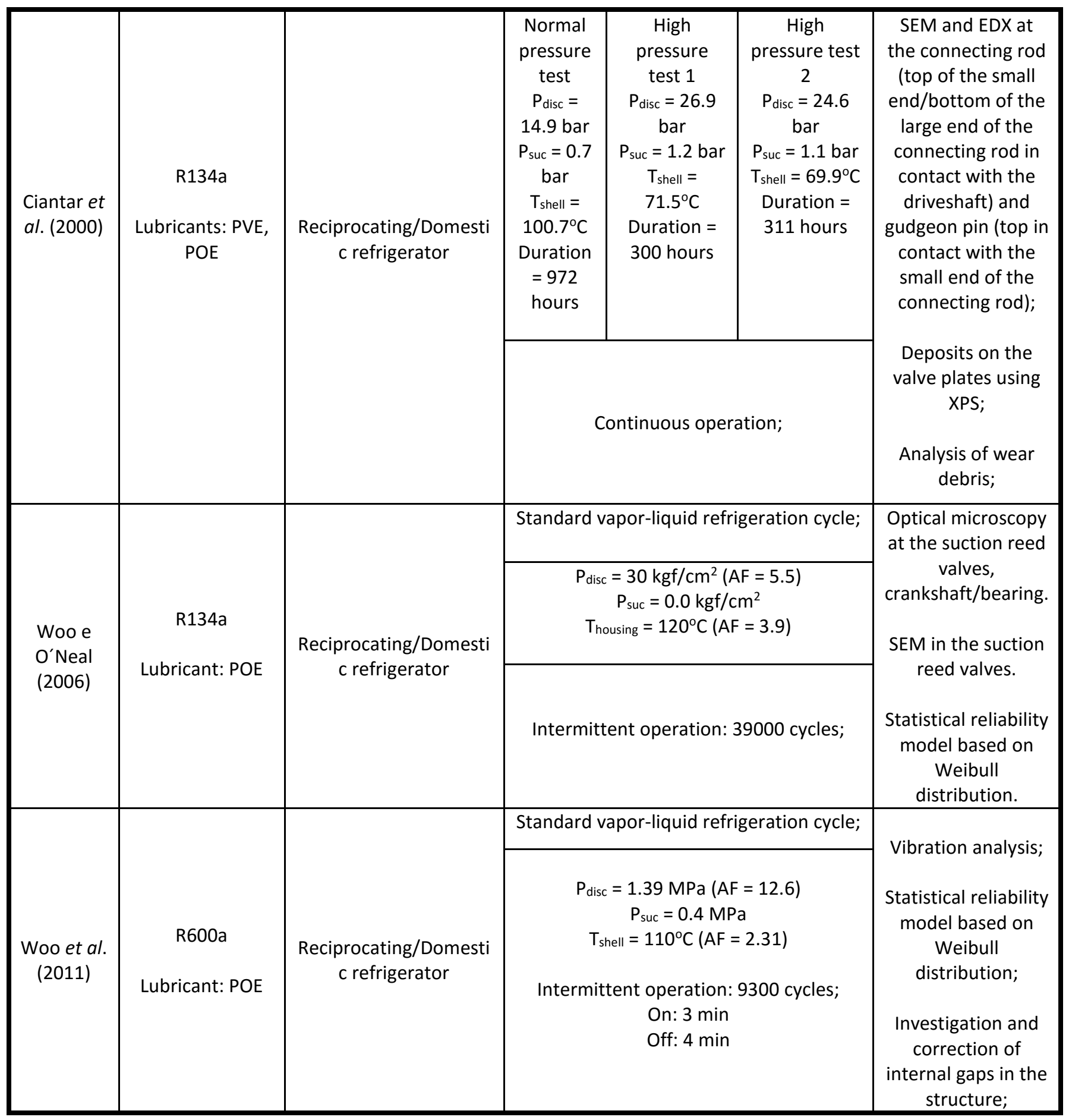

\section{CONCLUSIONS}

The objective of this paper is discuss the literature on accelerated life testing of reciprocating hermetic compressors, focusing on the wear of mechanical components._Test methodologies as well the procedures used to wear quantification are reasoned.

A critical analysis of scientific literature provides the following notes:

a) Reliability/durability studies of compressors that use natural refrigerants (hydrocarbons, $\mathrm{CO}_{2}$ ) are very incipient. 
b) Although R600a (and R290) is extensive refrigerant in use actually, there are no consolidated studies on long term tribological behaviour of compressors.

c) Phenomenological studies (development of new materials and surface coatings) are well established. It is important to compressor evaluation as part of a system. This basic principle of classical science can be applied analytically in a variety of directions, e.g., resolution of causal relations into separate parts (Czichos, 1978).

d) The correlation of wear reliability through a statistical life model is not yet established. Only Woo and O'Neal (2006), Woo et al., (2011) show statistical correlation (Weibull distribution) with the Arrhenius degradation model.

e) Lack of wear evolution and quantification based on the contact mechanics criteria and entropy production model. That is, the degradation of the rubbing materials is also a thermodynamically driven process.

f) Standardization scarcity for wear tests (durability) in hermetic compressors.

g) Inconsistency in determining the tests duration. The authors stipulate random periods without reference to the acceleration factors.

h) Need to set acceleration parameters for the scuffing failure.

i) The Theory of Intelligent Machines has been developed by Musto and Saridis (1993) as an analytical technique for intelligent control system design. Since this theory utilizes entropy as a cost function for intelligent control, the techniques used for entropy minimization can also be used for reliability optimization. In this approach, no probability distributions must be developed or numerically integrated. This is the future development.

\section{ACKNOWLEDGEMENTS}

We acknowledge financial support from CNPq agency through the Research Project 488068/2013-4.

\section{REFERENCES}

1. BAYLE, F., METTAS, A. Temperature acceleration models in reliability predictions: justification and improvements. Reliability and Maintainability Symposium, San Jose, USA, 2010.

2. BULNES, R., LARA, T., CRUZ, M. Confiabilidad de Sistemas Basado en la Tribología Disipada por la Fricción Mecanoquimica. II Conferencia en Confiabilidad Operacional - CCO. Universidad Simón Bolivar. 2012.

3. CIANTAR, C., HADFIELD, M., SWALLOW, A., SMITH, A. The influence of lubricant viscosity on the wear of hermetic compressor components in HFC-134a environments. Wear 236 (1999). $1-8$.

4. CIANTAR, C., HADFIELD, M., SWALLOW, A., SMITH; A. The influence of POE and PVE lubricant blends within hermetic refrigerating compressors operating with HFC-134a refrigerant. Wear, Volume 241, Issue 1, June 2000, Pages 53-64.

5. CIANTAR, C., HADFIELD, M. A study of tribological durability with associated environmental impacts of a domestic refrigerator. Materials and Design 25 (2004) 331-341. 
6. CHO, D.H., LEE, Y.Z. Comparison of scuffing life between unidirectional and reciprocating sliding motion. Wear 271 (2011) 1637-1641.

7. CZICHOS, H. Tribology: a systems approach to the science and technology of friction, lubrication and wear. Elsevier Scientific Pub. Co. ISBN 0444416765. 1978. 400 p.

8. De MELLO, J. D., B. R. BINDER, N. G. DEMAS, and A. A. POLYCARPOU. Effect of the Actual Environment Present in Hermetic Compressors on the Tribological Behaviour of a Si Rich Multifunctional DLC Coating. Wear, 267:5-8, 907-915, 2009.

9. DIRLEA, R., HANNAY, J., LEBRUN, J. Testing of Refrigeration Compressors without Condensation. International Compressor Engineering Conference Purdue University-USA. Paper 1113. 1996.

10. ERDMAN, E. Compressor Application Life Testing. International Compressor Engineering Conference Purdue University-USA. Paper 23. 1972.

11. FELDHAUS, D., COIT, D.W. Overview of Accelerated Life Testing Procedures for Reciprocal Compressors. International Compressor Engineering Conference Purdue University-USA. Paper 1342. 1998.

12. GARLAND, N.P., HADFIELD, M. Environmental implications of hydrocarbon refrigerants applied to the hermetic compressor. Materials and Design 26 (2005) 578-586.

13. HANSEN, P.F., FINSEN, L. Lifetime and Reliability of Small Hermetic Compressors Using a Ternary Blend HCFC-22/HFC-152a/HCFC-124. International Compressor Engineering Conference Purdue University USA. Paper 204. 1992.

14. HAWKEN, P., LOVINS, A. B., LOVINS, L. H. Natural Capitalism. The Next Industrial Revolution. Earthscan Publications. 1999.

15. HRNJAK, P. Thermodynamic possibilities and technological opportunities for improving the science of refrigeration in search for low global warming potential thermal systems. International Symposium on Next-generation Air Conditioning and Refrigeration Technology. 2010. Tokyo. Japan.

16. IIZUKA, T., ISHIYARNA, A., HATA, H., SATO, K. Reliability Study HFC134a Compressor for Refrigerator. International Compressor Engineering Conference. Purdue University USA. Paper 1119. 1996.

17. KLAMECKI, B.E. Wear - An entropy production model. Wear 58 (1980) 325-330.

18. LORENZ, A., ROCHHAUSEN, D. Verifying the reliability of Hermetically Sealed Compressors During Design With Special Regard to Wear Resistance. International Compressor Engineering Conference. Purdue University USA. Paper 238. 1976.

19. MEEKER, W.Q., ESCOBAR, L.A., LU, C.J. Accelerated degradation tests: Modeling and Analysis. Technometrics 40, 89-99. 1998.

20. MEEKER, W.Q., SARAKAKIS, G., GEROKOSTOPOULOS, A. More Pitfalls of Accelerated Tests. Available in:http://www.stat.iastate.edu/preprint/articles/2012-05.pdf. 2012.

21. MISHRA, S.P., POLYCARPOU, A.A. Tribological studies of unpolished laser surface textures under starved lubrication conditions for use in air-conditioning and refrigeration compressors. Tribology International 44 (2011) 1890-1901. 
22. MUSTO, J.C., SARIDIS, G.N. Entropy-based reliability analysis for intelligent machines. IEEE Transactions on Systems, Man, and Cybernetics, Part B: Cybernetics. Volume 27 Issue 2, April 1997 Page 239-244.

23. NA, B.C., CHUN, K.J., HAN, D.C. A tribological study of refrigeration oils under HFC- 134a environment. Tribology International 1997;30(9):707-16. 1997.

24. NELSON, W.B. Accelerated Testing: Statistical models, Test Plans and Data Analysis. John Wiley and Sons Publication. 610 pages. 1992.

25. NISHIOKA, K. Our Rapid Advances Have Prepared Us for the Demands of the Future. International Compressor Engineering Conference. Purdue University USA. Paper 1498. 1998.

26. PERRY, S.S., TYSOE, W.T. Frontiers of fundamental tribological research. Tribology Letters, 2005, 19(3): 151-161.

27. SAFARI, S., HADFIELD, M. Wear Behavior of the Piston-Gudgeon Pin in a Hermetic Compressor With Replacement of CFC Refrigerant. Wear (219), 1998, pp. 8-15.

28. SARIIBRAHIMOGLU, K., KIZIL, H., Aksit, M.F., Efeoglu, I., Kerpicci, H. 2010. Effect of R600a on tribological behavior of sintered steel under starved lubrication. Tribology International 43 (2010) 1054-1058.

29. SEKIYA, S., SHIRAFUJI, Y., KAWAGUCHI, S., KATO, T., IZAWA, T. Alkylbenzenes for Split AirConditioners with R-410A Part 1: Reliability Evaluation of Compressors. International Compressor Engineering Conference. Purdue University USA. Paper 1283. 1998.

30. SLAYTON, C., SPAUSCHUS, H. A Short Term, Accelerated Test Method for Rotary Compressors. International Compressor Engineering Conference. Purdue University-USA. Paper 1207. 1998.

31. SUESS, J., RASMUSSEN, R.D., JAKOBSEN, A. Impact of Refrigerant Fluid Properties on the Compressor Selection. International Compressor Engineering Conference. Purdue UniversityUSA. Paper 1388. 2000.

32. SUH, A.Y., PATEL, J.J., POLYCARPOU, A.A., CONRY, T.F. Scuffing of cast iron and Al390-T6 materials used in compressor applications. Wear 260 (2006) 735-744.

33. SUNAMI, M., SAWADA, K., FUKUNAGA, Y., SASAKI, U., SHIMOMURA, Y. Compressor Durability Tests and System Tests with Abs and HFCs. International Refrigeration and Air Conditioning Conference, Paper 436. 1998.

34. SUNAMI, M., SAITO, M., TAKIGAWA, K., SUDA, S., SASAKI, S. Lubricity of AB and AB Derivatives in Compressor Durability Tests. International Refrigeration and Air Conditioning Conference, Paper 341. 1996.

35. TOMIYAMA, T., UMEDA, Y. Life cycle design for the post mass production paradigm. In: Jin, Y. and Lu, S., (eds.) Proceedings of the CIRP 1997 International Design Seminar on Multimedia Technologies for Collaborative Design and Manufacturing, Los Angeles, University of Southern California, pp. 117-125. 1997.

36. WOO, S., O' NEAL, D.L. Reliability Design of the Newly Designed Reciprocating Compressor for a Refrigerator. International Compressor Engineering Conference.Purdue University USA. Paper 1818. 2006.

37. WOO, S-W., PARK, J., PECHT, M. Reliability design and case study of refrigerator parts subjected to repetitive loads under consumer usage conditions. Engineering Failure Analysis 
18 (2011) 1818-1830.

38. YANG, C., Role of surface roughness in tribology: from atomic to macroscopic scale. ISSN 18661807. Schriften des Forschungszentrums Jülich. 2008.

39. YOON, H.K., CUSANO, C. Scuffing Under Starved Lubrication Conditions. Air Conditioning and Refrigeration Center. College of Engineering. University of Illinois at Urbana-Champaign. ACRC Technical Report 147. 1999. 